\title{
Correction to: Applying a Precautionary Approach to Mobile Contact Tracing for COVID-19: The Value of Reversibility
}

\author{
Niels Nijsingh $(\mathbb{D} \cdot$ Anne van Bergen • Verina Wild
}

Published online: 12 May 2021

(C) The Author(s) 2021

This paper was previously published without the following funding details: This article was supported by the Bundesministerium für Bildung und Forschung (BMBF), grant number FKZ 01GP1791. The original article has been corrected.

The online version of the original article can be found at https://doi.org/10.1007/s11673-020-10004-z

N. Nijsingh $(\bowtie) \cdot$ A. van Bergen $\cdot$ V. Wild Institute for Ethics, History and Theory of Medicine, Ludwig Maximilians Universität, Lessingstrasse 2, 80336 München, Germany

e-mail: nielsnijsingh@posteo.net 